\title{
Two Cases of Tracheal Disease Misdiagnosed as Difficult-to-Treat Asthma
}

\author{
Ibrahim Onur Alici MD, Ozlem Kar Kurt MD, Adile Berna Dursun MD, \\ Aydin Yilmaz MD, and Ferda Oner Erkekol MD
}

\begin{abstract}
Initial management of patients with difficult-to-treat asthma must begin with confirmation of the diagnosis. We present 2 cases of tracheal disease misdiagnosed as difficult-to-treat asthma. After systemic evaluation, tracheomalacia and tracheobronchial narrowing due to diffuse calcification of the cartilaginous rings were found as mimicking asthma. Key words: flow limitation; asthma; difficult-to-treat asthma; severe asthma; tracheal calcification; tracheobronchomalacia. [Respir Care 2013;58(11):e133-e137.
\end{abstract} (c) 2013 Daedalus Enterprises]

\section{Introduction}

Asthma is a serious disease with high social and economic costs, and affects approximately 300 million individuals worldwide. ${ }^{1,2}$ The prevalence of asthma varies by country, between $1 \%$ and $18 \%{ }^{2}$ and is $1-9.4 \%$ in Turkey. ${ }^{3}$ Proper treatment (ie, corticosteroids) results in a good control; however, some patients remain symptomatic despite treatment, and systematic assessment of these patients must begin with confirmation of the diagnosis. ${ }^{4}$ We present 2 cases of tracheal disease misdiagnosed as difficult-to-treat asthma, in order to highlight the importance of systemic assessment.

\section{Case Report 1}

A 46-year-old female patient was referred to the allergy department with the diagnosis of difficult-to-treat asthma

Dr Alici is affiliated with the Department of Chest Diseases, Occupational Disorders Hospital, Ankara, Turkey. Dr Kar Kurt is affiliated with the Department of Chest Diseases, Abant Izzet Baysal University Faculty of Medicine, Bolu, Turkey. Drs Dursun and Erkekol are affiliated with the Department of Allergy and Clinical Immunology; and Dr Yilmaz is affiliated with the Department of Interventional Pulmonology, Atatürk Chest Diseases and Thoracic Surgery Education and Research Hospital, Ankara, Turkey.

The authors have disclosed no conflicts of interest.

Correspondence: Ozlem Kar Kurt MD, Department of Chest Diseases, Abant Izzet Baysal University Faculty of Medicine, 14280 Bolu, Turkey. E-mail: aghhozlem@yahoo.com.

DOI: $10.4187 /$ respcare. 02350 in 2011. Her complaints of productive cough and gradually exacerbating shortness of breath began approximately 9 years earlier. She was followed-up numerous times at several in-patient clinics, with the diagnosis of exacerbation of asthma, particularly during winter, despite regular use of asthma medication. At the time of her referral she was taking formoterol/budesonide $12 \mu \mathrm{g} / 400 \mu \mathrm{g}$ twice a day. The patient had never smoked. She underwent surgery due to chronic rhinosinusitis 9 years ago.

Her physical examination showed bilateral expiratory rhonchi. Pulmonary function test results showed markedly diminished expiratory flow, with no reversibility: $\mathrm{FEV}_{1} 20 \%$ of predicted, $\mathrm{FEV}_{1} / \mathrm{FVC} 42 \%$ of predicted, FVC $41 \%$ of predicted, peak expiratory flow $84 \mathrm{~L} / \mathrm{min}$, forced expiratory flow during the middle half of the FVC maneuver $\left(\mathrm{FEF}_{25-75 \%}\right) 10 \%$ of predicted (Fig. 1). Chest $\mathrm{x}$-ray showed rough narrowing of the trachea and main bronchi, and bilateral irregular infiltration in the basal segments (Fig. 2). She declined flexible bronchoscopy, but consented to 3-dimensional computed tomography (Fig. 3). The cartilage rings of the trachea and main bronchi were diffusely calcified, which resulted in diffuse narrowing of the lumen, by as much as $7 \mathrm{~mm}$. In addition, peribronchial thickening, focal air-trapping, and peripheral reticulonodular infiltration were observed. Comparison of the images with tomograms from 2007 showed progression of airway disease.

She was referred to the interventional bronchology and thoracic surgery departments, and both departments concluded that interventional bronchoscopy and surgery would not benefit the patient. She refused additional diagnostic studies. With antibiotics her symptoms resolved, but there 


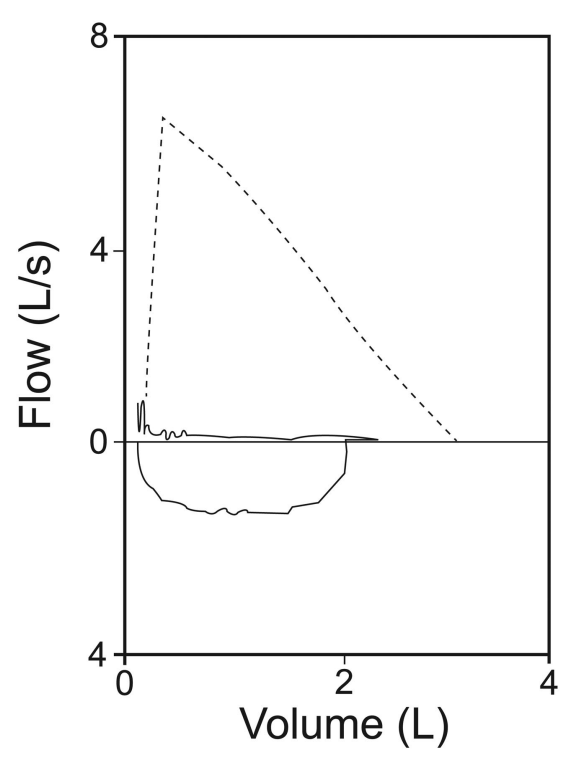

Fig. 1. Case 1. Flow-volume curve shows severe fixed flow limitation.

was no improvement in expiratory flow, and she was discharged and referred to the pulmonary rehabilitation department. The final diagnosis was diffuse tracheobronchial calcification.

\section{Case Report 2}

A 37-year-old-female patient was referred to the allergy department with the diagnosis of difficult-to-treat asthma in 2011. Episodic dyspnea began during childhood, and she was diagnosed with asthma 7 years earlier. She was taking systemic corticosteroid from 2009 to 2011, due to her ongoing complaints and frequent emergency room visits despite high-dose inhaled corticosteroid and long-acting $\beta_{2}$ agonist and leukotriene receptor antagonist. She reported regular use of all those medications, but remained symptomatic. She complained of wheezing and dyspnea during the day, and reported that during the previous month she could not go to work. The patient had never smoked and had no comorbidities.

Physical examination showed bilateral inspiratory and expiratory rhonchi. Pulmonary function test results showed expiratory flow limitation: $\mathrm{FEV}_{1} 34 \%$ of predicted, $\mathrm{FEV}_{1}$ / FVC $66 \%$ of predicted, FVC $45 \%$ of predicted, peak expiratory flow $238 \mathrm{~L} / \mathrm{min}, \mathrm{FEF}_{25-75 \%} 17 \%$ of predicted (Fig. 4). Thoracic computed tomography showed tracheoles neighboring the posterior wall of the trachea (Fig. 5). Fiberoptic bronchoscopy showed that the posterior membranous wall of the trachea and bronchi was grossly bulging into the lumen during expiration (Fig. 6). This finding was consistent with tracheobronchomalacia.

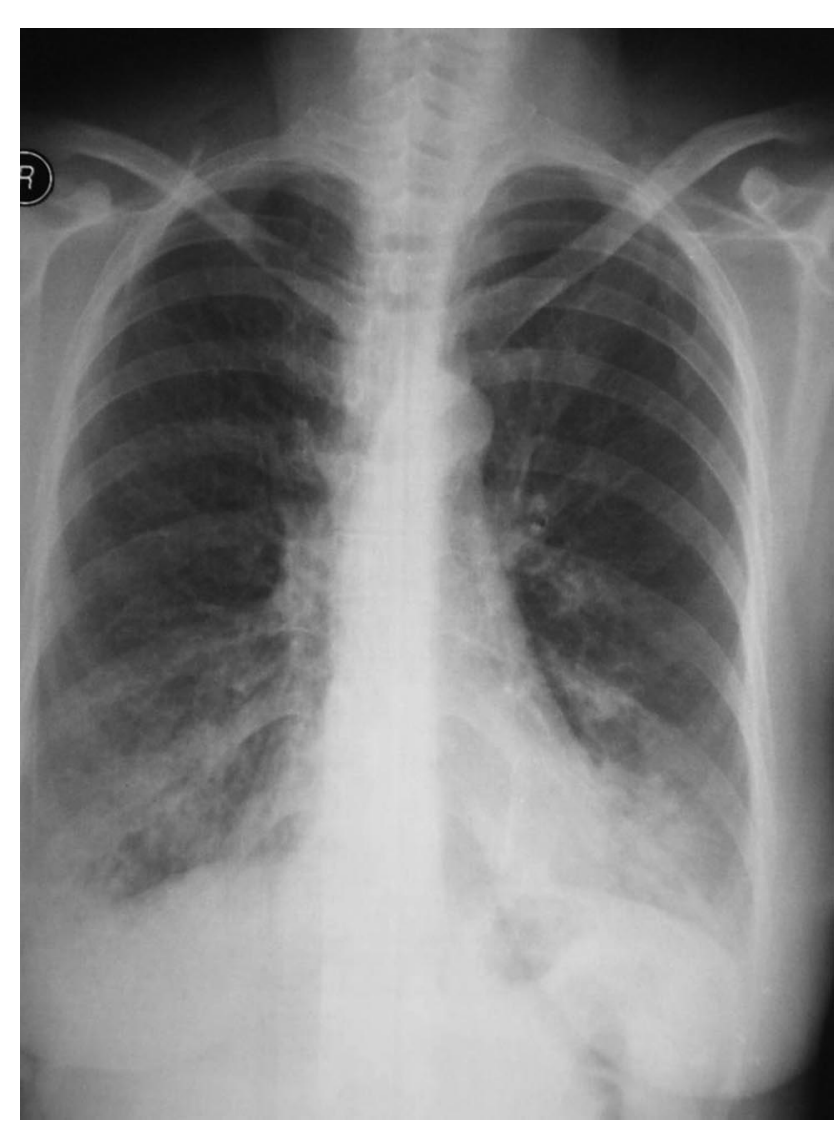

Fig. 2. Case 1. Chest $x$-ray shows diffuse narrowing of the airways and bilateral infiltration in the basal segments.

The patient was referred to the interventional pulmonology department for stent placement, and the thoracic surgery department for surgical intervention, but the respective departments concluded that stent placement and surgery were inappropriate, due to diffuse involvement of the trachea and large bronchi.

\section{Discussion}

Difficult-to-treat asthma patients remain symptomatic despite high-doses of $\geq 2$ asthma control drugs. ${ }^{2}$ Such patients usually undergo systemic corticosteroid treatment for many years and therefore experience the systemic side effects of such medication. Treatment of difficult-to-treat asthma patients must be systematically based and begin with confirmation of the diagnosis. ${ }^{2}$ Cough, wheezing, and dyspnea are common respiratory symptoms that potentially have an extensive differential diagnosis. Although asthma is the most common cause of cough, wheeze, and dyspnea in all ages, asthma is often attributed inappropriately to symptoms from other causes. ${ }^{5}$ Differential diagnosis in adults includes the presence of COPD, vocal cord dysfunction, and benign or malignant diseases of the tracheobronchial tree (Table). 6,7 

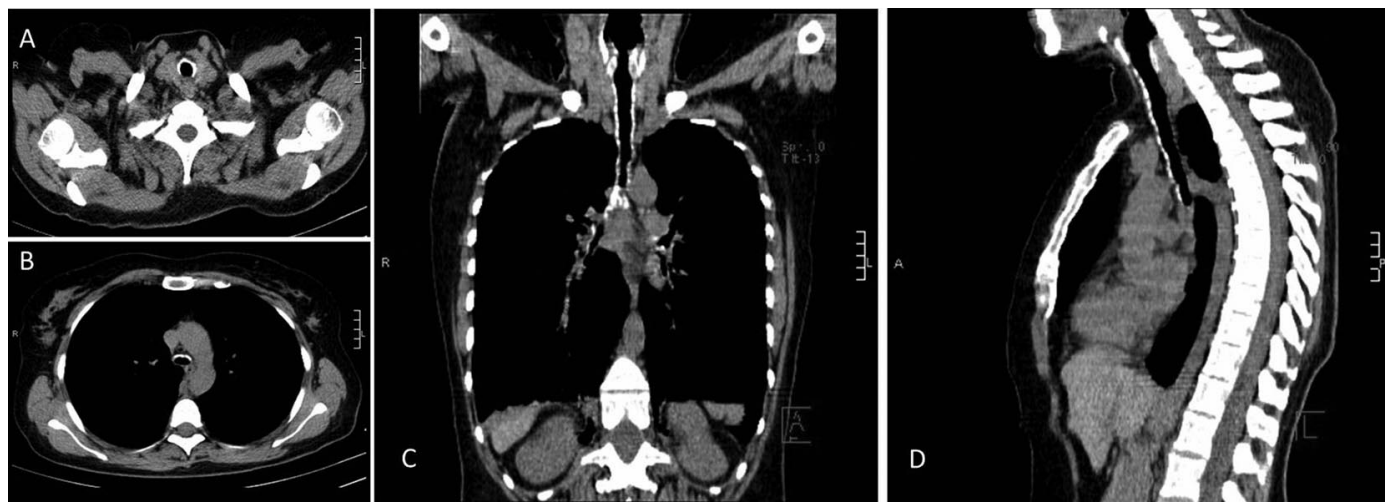

Fig. 3. Case 1. Transverse computed tomography sections at the upper (A) and lower (B) trachea. Reconstructed images of the thorax: (C) coronal view, (D) sagittal view. There is diffuse calcification of the tracheobronchial cartilaginous rings and narrowing of the tracheobronchial tree.

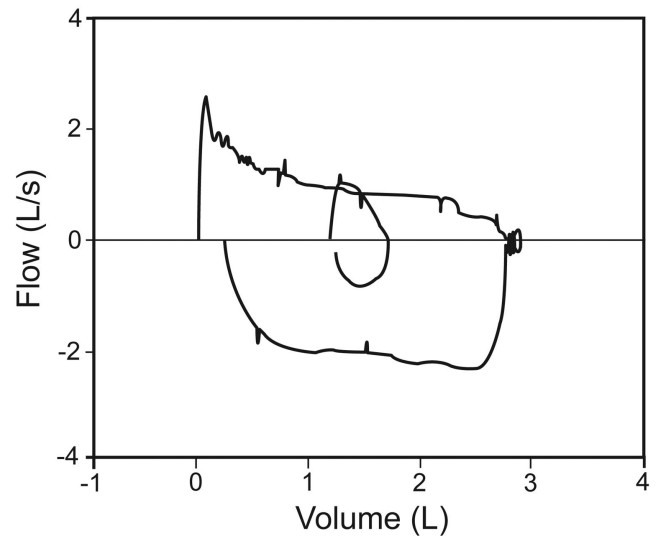

Fig. 4. Case 2. Flow-volume curve shows severe expiratory flow limitation.

The presented cases of benign tracheal disease that were misdiagnosed as asthma were using $>2$ asthma control medications, had frequent hospitalizations, and took systemic corticosteroids for many years. Both patients were housewives and did not have any environmental or occupational exposure. Case 1 had diffuse narrowing of the tracheobronchial system due to diffuse calcification of the cartilaginous rings. Tracheal calcification can be observed in relapsing polychondritis, tracheobronchopathia osteochondroplastica, amyloidosis, rhinoscleroma, and Keutel syndrome.

Relapsing polychondritis is a rare autoimmune syndrome characterized by recurrent cartilaginous inflammation, with destruction and fibrosis. ${ }^{8}$ Various cartilaginous structures, such as the ear, nose, joints, larynx, and tracheobronchial tree, may be involved. ${ }^{9}$ Thickening of the tracheal wall and destruction of the cartilaginous rings are key findings, whereas the posterior membranous region is spared. ${ }^{10} \mathrm{Di}-$ agnosis is based on the presence of $\geq 3$ of: bilateral auricular chondritis, non-erosive seronegative inflammatory polyarthritis, nasal chondritis, ocular inflammation, respi-

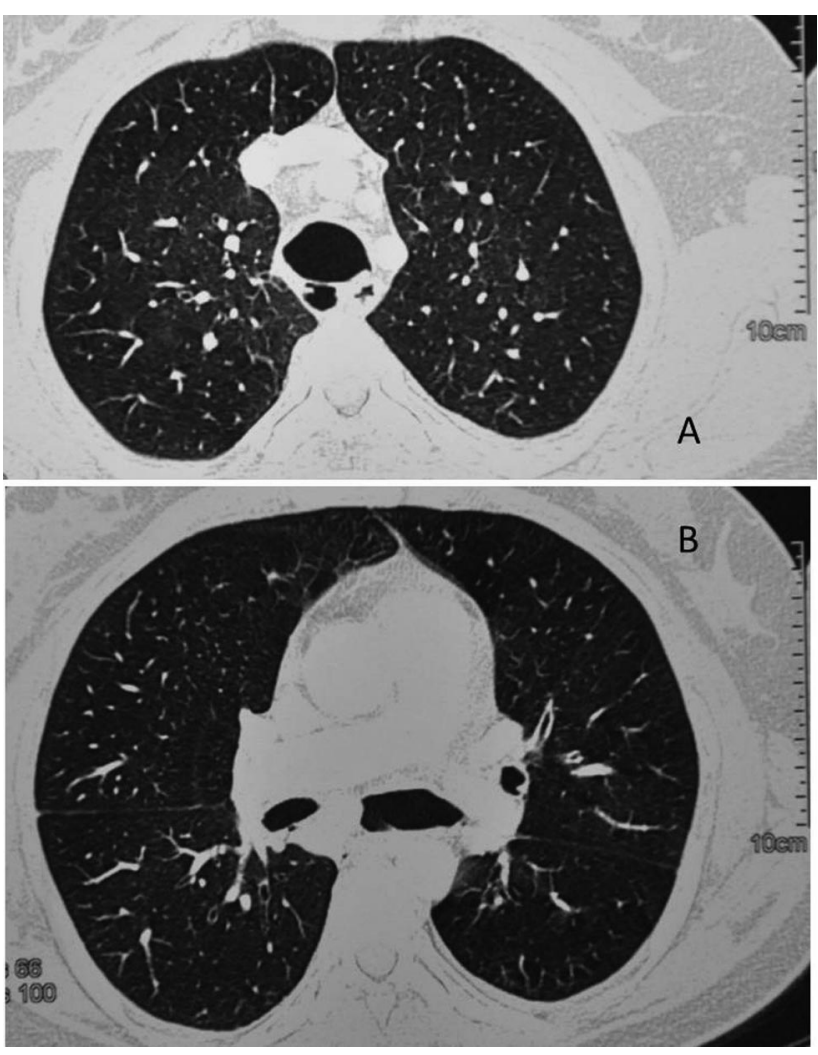

Fig. 5. Case 2. Thoracic computed tomography shows increased tracheal $(A)$ and main bronchi $(B)$ diameters.

ratory tract chondritis, and audio vestibular damage. The tracheobronchial tree in case 1 was diffusely involved. The disease had progressed during the previous 4 years. The patient's tracheobronchial cartilaginous rings were diffusely calcified, but not destroyed. Deformation of nasal cartilage was evident, and she complained of difficulty hearing, though there were no signs of auricular chondritis. She reported no history of ocular inflammation or poly- 


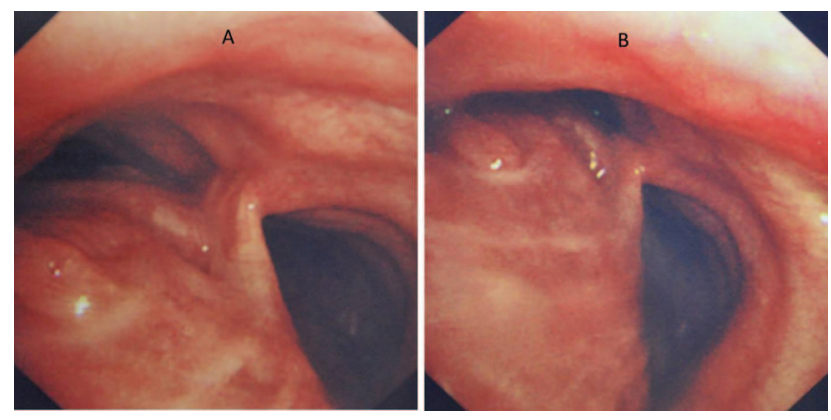

Fig. 6. Case 2. Fiberoptic bronchoscopy shows increased airway size during inhalation $(A)$ and collapse during exhalation $(B)$.

Table. Conditions That Mimic Severe Treatment-Resistant Asthma

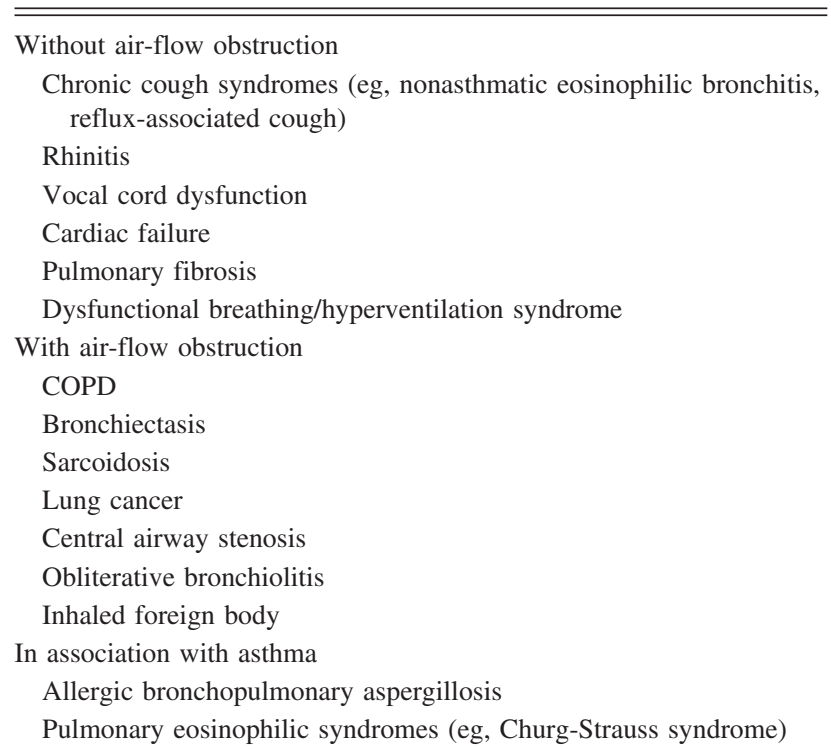

(From data in reference 6.)

arthritis, and, as such, relapsing polychondritis was considered a possible diagnosis.

Tracheobronchopathia osteochondroplastica and amyloidosis are diseases of submucosal tissue. ${ }^{8}$ The former is characterized by multiple submucosal osteocartilaginous nodules that spare the posterior membrane of airways. The latter is deposition of abnormal proteinaceous material in extracellular tissue. There are 3 forms of amyloidosis: diffuse interstitial deposits, single or multiple pulmonary nodules, and, most commonly, submucosal tracheobronchial deposits. ${ }^{11}$ Submucosal tracheobronchial deposits usually exhibit calcification. ${ }^{12}$ Amyloidosis is differentiated from tracheobronchopathia osteochondroplastica by involvement of the posterior membrane. Case 1 had calcified cartilaginous rings and the submucosal area was spared.

Rhinoscleroma is a chronic, progressive granulomatous Klebsiella rhinoscleromatis infection that affects the upper and lower respiratory tract. ${ }^{13}$ Tracheobronchial disease is not common. ${ }^{14}$ Thickening of the tracheal wall, nodular deformity of mucosa, subglottic stricture, and concentric narrowing of the trachea and central bronchi are the main radiologic findings. ${ }^{15}$ A positive Klebsiella rhinoscleromatis culture is diagnostic but is observed in $<60 \%$ of cases. ${ }^{16}$ Radiologic features in case 1 were consistent with the disease, but we could not obtain a specimen for microbiological investigations, because the patient did not consent.

Keutel syndrome is a rare syndrome characterized by brachytelephalangism, abnormal cartilage calcification, neural hearing loss, and peripheral pulmonary stenosis. ${ }^{17}$ Most Keutel syndrome patients are children and young adults. Case 1 was 46 years old, and onset of the disease occurred when the patient was 9 years old. The disease radiologically had progressed during the previous 4 years, in the absence of other systemic features.

Case 2 was diagnosed as tracheobronchomalacia, which is characterized by a weak trachea and main bronchi. ${ }^{18}$ Normal intrathoracic airways dilate during inspiration and narrow during expiration, according to changes in intrathoracic pressure during the respiratory cycle. Tracheobronchomalacia can be congenital, but is more commonly acquired. Prolonged intubation, tracheostomy, external trauma, emphysema, and chronic infections are the most common etiological factors in adult tracheobronchomalacia. ${ }^{18}$ Many of these conditions create segmental involvement of the airway, whereas chronic infections and emphysema are usually related to diffuse disease. The most common symptoms of tracheobronchomalacia are dyspnea, wheezing, cough, and sputum production. Diagnosis is usually based on fiberoptic bronchoscopic visualization of $>50 \%$ tracheal narrowing during expiration. ${ }^{18}$ Treatment is usually conservative, but in severe cases CPAP, stent placement, or surgical interventions are indicated.

Congenital tracheobronchomalacia was considered as a diagnosis in case 2 , because her complaints began in childhood; however, it was rejected because diffuse disease is usually related to congenital anomalies and syndromes associated with other systems that are diagnosed during infancy, and to some cartilage abnormalities with involvement of other cartilaginous structures. ${ }^{18}$

Asthma is the most common disease in the differential diagnosis of limited expiratory flow. Many tracheobronchomalacia patients receive asthma medications prior to the definitive diagnosis. Case 2 had received almost all available asthma medications for 3 years. As the trachea and main bronchi were diffusely involved, we concluded that chronic infections were the cause of the patient's symptoms.

Difficult-to-treat asthma patients must be systematically evaluated via differential diagnosis. Many diverse conditions must be responsible from expiratory flow limitation. Definitive diagnosis of underlying disease is crucial in 


\section{Two Cases of Tracheal Disease Misdiagnosed as Difficult-to-Treat Asthma}

order to avoid unnecessary long-term high-dose corticosteroid treatment, which can have severe systemic side effects rather than therapeutic action.

\section{REFERENCES}

1. Masoli M, Fabian D, Holt S, Beasley R. The global burden of asthma: executive summary of the GINA Dissemination Committee report. Allergy 2004;59(5):469-478.

2. Masoli M, Fabian D, Holt S, Beasley R; Global Initiative for Asthma (GINA). Global burden of asthma. http://ginasthma.org/local/uploads/ files/GINABurdenReport_1.pdf. Accessed August 27, 2013.

3. Turkish Thoracic Society. Asthma diagnosis and treatment guideline. Guideline in Turkish. 2009. http://www.toraks.org.tr/book. aspx?list=72. Accessed August 27, 2013.

4. Robinson DS, Campbell DA, Durham SR, Pfeffer J, Barnes PJ, Chung KF. Systematic assessment of difficult-to-treat asthma. Eur Respir J 2003;22(3):478-483.

5. Weinberger M, Abu-Hasan M. Pseudo-asthma: when cough, wheezing, and dyspnea are not asthma. Pediatrics 2007;120(4):855-864.

6. British Thoracic Society. Sign asthma guidelines 2011. http://www. brit-thoracic.org.uk/Portals/0/Guidelines/AsthmaGuidelines/ sign101\%20Jan\%202012.pdf. Accessed August 23, 2013.

7. Siddiqui S, Gonem S, Wardlaw AJ. Advances in the management of severe asthma. Semin Respir Crit Care Med 2012;33(6):666-684.

8. Prince JS, Duhamel DR, Levin DL, Harrell JH, Friedman PJ. Nonneoplastic lesions of the tracheobronchial wall: radiologic findings with bronchoscopic correlation. Radiographics 2002;(22 Spec No): S215-S230

9. Davis SD, Berkmen YM, King T. Peripheral bronchial involvement in relapsing polychondritis: demonstration by thin-section CT. AJR 1989;153(5):953-954.

10. Kwong JS, Muller NL, Miller RR. Diseases of the trachea and mainstem bronchi: correlation of CT with pathologic findings. Radiographics 1992;12(4):645-657.

11. Rubinow A, Celli BR, Cohen AS, Rigden BG, Brody JS. Localized amyloidosis of the lower respiratory tract. Am Rev Respir Dis 1978; 118(3):603-611.

12. Gross BH, Felson B, Birnberg FA. The respiratory tract in amyloidosis and the plasma cell dyscrasias. Semin Roentgenol 1986;21(2): 113-127.

13. Yigla M, Ben-Izhak O, Oren I, Hashman N, Lejbkowicz F. Laryngotracheobronchial involvement in a patient with nonendemic rhinoscleroma. Chest 2000;117(6):1795-1798.

14. Soni NK. Scleroma of the lower respiratory tract: a bronchoscopic study. J Laryngol Otol 1994;108(6):484-485.

15. Stark P. Radiology of the trachea. New York: Thieme; 1991.

16. Omeroglu A, Weisenberg E, Baim HM, Rhone DP. Pathologic quiz case. Supraglottic granulomas in a young Central American man. Arch Pathol Lab Med 2001;125(1):157-158.

17. Meier M, Weng LP, Alexandrakis E, Ruschoff J, Goeckenjan G. Tracheobronchial stenosis in Keutel syndrome. Eur Respir J 2001; 17(3):566-569.

18. Carden KA, Boiselle PM, Waltz DA, Ernst A. Tracheomalacia and tracheobronchomalacia in children and adults: an in-depth review. Chest 2005;127(3):984-1005. 